\title{
Alternativas para o controle de emissões odorantes em reatores anaeróbios tratando esgoto doméstico
}

\section{Alternatives for the control of odorous emissions in anaerobic reactors treating domestic wastewater}

\author{
Carlos Augusto de Lemos Chernicharo \\ Professor Associado do Departamento de Engenharia Sanitária e Ambiental da Universidade Federal de Minas Gerais (UFMG) \\ Richard Michael Stuetz \\ Professor Associado da University of New South Wales, Sydney, Austrália
}

Cláudio Leite Souza

Doutorando do Programa de Pós-graduação em Saneamento, Meio Ambiente e Recursos Hídricos da Escola de Engenharia da UFMG

\section{Gilberto Caldeira Bandeira de Melo}

Professor Associado do Departamento de Engenharia Sanitária e Ambiental da UFMG

\begin{abstract}
Resumo
Esta nota técnica busca consolidar as principais características, vantagens e desvantagens dos métodos usualmente empregados para o controle de emissões odorantes, discorrendo criticamente acerca da aplicabilidade de cada um dos métodos para o tratamento de odores em estações de tratamento de esgoto doméstico. Verificou-se que vários métodos são sofisticados, de elevado custo e, muitas vezes, não aplicáveis ao tratamento de odores emitidos em reatores anaeróbios tratando esgoto doméstico. Uma análise qualitativa dos vários métodos indica que a combustão direta e os processos bioquímicos são os que reúnem o maior conjunto de vantagens para o tratamento de gases residuais emitidos em reatores anaeróbios.
\end{abstract}

Palavras-chave: controle de odor; reatores anaeróbios; sulfeto de hidrogênio; tratamento de esgoto.

\begin{abstract}
This technical note aims at consolidating the main characteristics, advantages and disadvantages of the methods usually applied to the control of odorous emissions, with a critical analysis upon the applicability of each method to the treatment of odours in treatment plants of domestic wastewater. It was verified that several methods are sophisticated, present high cost, and are often non-applicable to the treatment of odour emissions from anaerobic reactors treating domestic wastewater. The qualitative analysis of the various methods points out that direct combustion and biochemical processes gather more advantages for the treatment of waste gases produced in anaerobic reactors.
\end{abstract}

Keywords: odour control; anaerobic reactors; hydrogen sulfide; wastewater treatment

\section{Introdução}

A emissão de gases odorantes em reatores anaeróbios é um problema de grande importância e, se não resolvido, poderá prejudicar significativamente a aplicação mais ampla da tecnologia anaeróbia no Brasil. Para evitar reclamações da população, várias estações de tratamento de esgoto estão gastando significativas quantidades de recursos com a aplicação de produtos químicos, objetivando minimizar ou mascarar a dispersão das emissões de sulfeto de hidrogênio $\left(\mathrm{H}_{2} \mathrm{~S}\right)$ no entorno das estações. Em boa parte dos casos, não existe uma indicação clara da origem da emissão, a qual pode estar relacionada com as características do esgoto afluente, com o desempenho do reator, ou com a descarga turbulenta do efluente.

No caso do esgoto doméstico, a decomposição anaeróbia da fração proteica contida na matéria orgânica é a principal causa da geração de odores, enquanto emissões diretas devido a produtos químicos específicos encontram-se usualmente associadas com a presença de efluentes industriais. Dependendo do precursor, do $\mathrm{pH}$ e do potencial de oxiredução, diferentes compostos odorantes são biologicamente formados na medida em que o esgoto se torna anaeróbio. $\mathrm{O}_{2} \mathrm{~S}$, resultante da 
redução biológica do sulfato $\left(\mathrm{SO}_{4}^{2-}\right)$ ou tiosulfato sob condição anaeróbia, é o composto odorante mais comumente associado aos odores do esgoto, embora outros compostos à base de enxofre também possam contribuir para esses odores (VAN LANGENHOVE; de HEYDER, 2001). Compostos orgânicos voláteis também têm sido identificados nos gases residuais de estações de tratamento de esgoto, mas a sua contribuição para os odores de esgoto é limitada em função de possuírem limites de percepção relativamente elevados em comparação aos compostos de enxofre (VAN LANGENHOVE; de HEYDER, 2001). Nos sistemas de coleta e interceptação de esgoto, a maior parte do sulfeto gerado ocorre na camada de biofilme fixada nas paredes das tubulações

Tabela 1 - Concentrações típicas de $\mathrm{H}_{2} \mathrm{~S}$ na atmosfera de diferentes unidades de estações de tratamento de esgoto doméstico e do sistema de esgotamento sanitário

\begin{tabular}{|c|c|c|c|}
\hline \multirow[t]{2}{*}{$\begin{array}{l}\text { Unidade do } \\
\text { sistema }\end{array}$} & \multicolumn{2}{|c|}{$\begin{array}{l}\text { Concentrações } \\
\text { médias ou } \\
\text { faixas de variação }\end{array}$} & \multirow[t]{2}{*}{ Referência } \\
\hline & $\mathrm{mg} / \mathrm{m}^{3}$ & ppm & \\
\hline \multirow{2}{*}{$\begin{array}{l}\text { Tubulação } \\
\text { de esgoto }\end{array}$} & 0 a 417 & 0 a 300 & Matos e Aires (1995) \\
\hline & 70 a 556 & 50 a 400 & Jobbágy et al (1994) \\
\hline \multirow{3}{*}{ Estação elevatória } & 4,8 & 3,3 & Bohn (1993) \\
\hline & 0,57 & 0,4 & Silva et al (2007) \\
\hline & 1 a 3 & 0,7 a 2,0 & $\begin{array}{l}\text { Antunes e Mano (2004) } \\
\text { apud Silva et al (2007) }\end{array}$ \\
\hline \multirow{2}{*}{$\begin{array}{l}\text { Unidade } \\
\text { pré-tratamento }\end{array}$} & 3,5 & 2,4 & Bohn (1993) \\
\hline & 2,8 a 51,5 & 2 a 37 & Al-Shammiri (2004) \\
\hline Desidratação lodo & 6,5 & 4,5 & Bohn (1993) \\
\hline Gás residual ${ }^{1}$ & 0 a 73 & 0 a 50 & $\begin{array}{l}\text { Pagliuso, Passig e Ville- } \\
\text { la (2002), Souza (2010), } \\
\text { Souza, Chernicharo e } \\
\text { Melo (2010) }\end{array}$ \\
\hline Gás residual $^{2}$ & 146 a 730 & 100 a 500 & $\begin{array}{l}\text { Pagliuso, Passig e } \\
\text { Villela (2002), Souza } \\
\text { (2010), }\end{array}$ \\
\hline
\end{tabular}

${ }^{1}$ Gás oriundo do compartimento de decantação de reator UASB

${ }^{2}$ Gás oriundo de caixa de dissipação localizada na linha de coleta do efluente de reator UASB

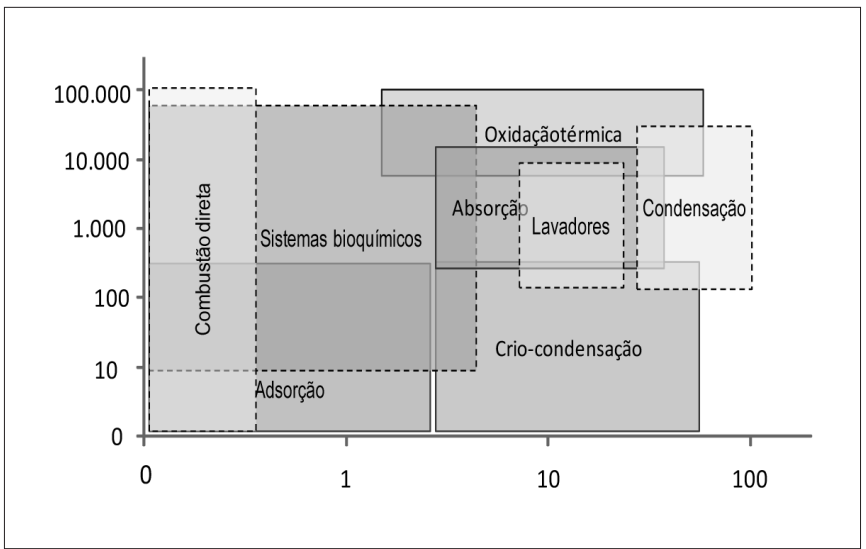

Figura1-Faixas deaplicaçãodediversastecnologiasparacontroledeodores Fonte: adaptado de Kennes et al (2001) e Noyola, Morgan-Sagastume e López-Hernández (2006). ou em depósitos de lodo, na parte inferior das tubulações (WEF, 2004). Na Tabela 1 são mostradas as concentrações típicas de $\mathrm{H}_{2} \mathrm{~S}$ na atmosfera de diferentes unidades de estações de tratamento de esgoto doméstico e do sistema de esgotamento sanitário.

\section{Alternativas para 0 controle de gases odorantes}

Os métodos para o controle de gases odorantes em estações de tratamento de esgoto podem ser caracterizados como de natureza física, química e bioquímica. A maioria dos métodos físicos e químicos foi desenvolvida nas últimas décadas, sendo, portanto, bem estabelecidos, enquanto os métodos bioquímicos são mais recentes e ainda se encontram em desenvolvimento. Nas Tabelas 2 a 4, são mostradas as principais tecnologias para controle de odores, assim como as principais características, vantagens e desvantagens de cada uma.

Embora existam diversas alternativas para o controle de emissões odorantes, a seleção de uma em particular ou a combinação de tecnologias depende de dois critérios principais: vazão de gás e concentração dos gases odorantes. A Figura 1 mostra as faixas típicas de aplicação de vários tipos de tecnologias para o controle de gases odorantes baseadas na concentração e na vazão do gás odorante. Pode-se observar que, para o caso de gases odorantes em baixas concentrações, a combustão direta, a adsorção e os métodos bioquímicos são os que encontram maior aplicação (Noyola, Morgan-Sagastume; López-Hernández, 2006)

No entanto, na seleção de alternativas para o controle de emissões odorantes em reatores anaeróbios, diversos outros critérios devem ser considerados, a exemplo de (adaptado de Burgess, Parsons e Stuetz, 2001 e Kennes et al, 2001): i) biodegradabilidade dos gases odorantes; ii) características locais, inclusive de recursos humanos; iii) origem das emissões e aspectos de projeto relacionados à captação e condução de gases; iv) concentração relativa de $\mathrm{H}_{2} \mathrm{~S}_{\mathrm{CH}} \mathrm{CH}_{4}$; v) planos para recuperação de energia; vi) objetivos do tratamento. A decisão sobre qual alternativa adotar para o controle das emissões odorantes deve resultar de um balanço entre critérios técnicos, econômicos e ambientais, levando-se em consideração os aspectos quantitativos e qualitativos de cada alternativa. A Figura 2 apresenta uma comparação

\begin{tabular}{|c|c|c|c|c|}
\hline & \multicolumn{2}{|c|}{ Países desenvolvidos } & \multicolumn{2}{|c|}{ Países em desenvolvimento } \\
\hline \multicolumn{5}{|l|}{ Eficiência } \\
\hline \multicolumn{5}{|l|}{ Confiabilidade } \\
\hline \multicolumn{5}{|c|}{ Disposição de subprodutos } \\
\hline \multicolumn{5}{|c|}{ Requisito de área } \\
\hline \multicolumn{5}{|c|}{ Impactos ambientais } \\
\hline \multicolumn{5}{|c|}{ Custos operacionais } \\
\hline \multicolumn{5}{|c|}{ Custos de construção } \\
\hline \multicolumn{5}{|c|}{ Sustentabilidade } \\
\hline \multicolumn{5}{|l|}{ Simplicidade } \\
\hline & Crítico & Importante & Importante & Critico \\
\hline
\end{tabular}

Figura2-Aspectos paraaseleção dealternativas paratratamento de odores Fonte: adaptado de von Sperling (1996). 
Tabela 2 - Principais características e análise comparativa dos principais métodos de tratamento físico de odores: balanço das vantagens e desvantagens

\begin{tabular}{ll} 
Método & Principais características \\
\hline & Refere-se à conversão de vapores em \\
& um líquido, seja pelo acréscimo da \\
& pressão e/ou pelo abaixamento da tem- \\
& peratura do sistema. As moléculas ficam \\
& mais próximas umas das outras devido \\
& à pressurização, enquanto o abaixa- \\
& mento da temperatura reduz a energia \\
& cinética. A condensação é geralmente \\
& aplicada para tratar emissões gasosas \\
Condensação & constituídas de um vapor poluente con- \\
& densável e um gás não-condensável.
\end{tabular}

Vantagens

- Custos de capital moderados, especialmente para condensadores de contato direto

- Custos operacionais moderados

- Possibilidade de recuperação e reúso de compostos de valor, uma vez que o poluente pode ser condensado e, portanto, separado da fase gasosa

Desvantagens

- Os poluentes são transferidos para uma nova fase ao invés de serem destruídos

- Aplicados principalmente para o prétratamento de compostos orgânicos voláteis (VOC) de elevada concentração (> 5.000 ppmv) e de relativa baixa vazão. A eficiência de tratamento é reduzida para poluentes menos concentrados ou de maior vazão. Poluentes muito voláteis são removidos apenas marginalmente

- No caso em que os compostos orgânicos voláteis ficam dissolvidos no líquido de resfriamento durante ou antes da condensação, os poluentes são transferidos para a fase líquida, tornando necessário o tratamento da água residuária gerada.

\begin{abstract}
- Refere-se ao processo em que as moléculas de compostos orgânicos voláteis entram em contato com a superfície de um adsorvente sólido e se ligam via forças moleculares fracas. A superfície de um adsorvente inclui todas as áreas acessíveis e pode, portanto, ser extensiva a sólidos que incorporam uma rede interna de poros, incluindo Adsorção aqueles com diâmetros de dimensões moleculares

- Um tratamento típico por adsorção consiste em uma coluna vertical, empacotada com meios suportes estáticos de material granular. O carvão ativado é o adsorvente mais comumente utilizado.
\end{abstract}

- Custos de capital moderados

- Mecanicamente simples

- Ocupam pequena área (devido ao baixo tempo de retenção)

- Estável e de desempenho elevado e confiável

- Pode remover seletivamente $\mathrm{H}_{2} \mathrm{~S}$ quando combinado com um adsorvente com afinidade pelo $\mathrm{H}_{2} \mathrm{~S}$ (ex. carvão ativado)
- Os poluentes são transferidos para uma nova fase ao invés de serem destruídos

- Custos operacionais muito elevados (substituição/regeneração do carvão ativado)

- Vida útil do carvão ativado reduzida pela umidade do gás

- Gera corrente secundária de resíduo (carvão não regenerável)

- Perda de carga mediana

- Somente aplicável para baixas cargas de contaminantes (para permitir vida útil aceitável para o carvão ativado)

- Pode ser um problema para a remoção seletiva de $\mathrm{H}_{2} \mathrm{~S}$ e recuperação de metano como biocombustível, uma vez que hidrocarbonetos são apenas ligeiramente polares e, portanto, são preferencialmente adsorvidos antes dos compostos polares, como $\circ \mathrm{H}_{2} \mathrm{~S}$.

- Refere-se à transferência dos poluentes presentes no gás residual para uma fase líquida não-volátil. Diferentemente dos lavadores químicos, água limpa é usualmente utilizada como líquido de lavagem, sem a adição de produtos Absorção químicos. As colunas empacotadas (Lavador são projetadas de maneira similar aos com água) lavadores químicos, objetivando a promoção de grande área interfacial entre o gás poluente e o adsorvente (água). A fase líquida contaminada resultante é usualmente tratada biologicamente $e$ recirculada para o lavador.

- O princípio de separação por membrana é o de que alguns compostos da corrente gasosa são transportados através de uma membrana delgada enquanto outros são retidos. A permeabilidade é uma função direta da solubilidade

Separação química do composto de interesse, na membrana.

por membrana

- Membranas sólidas podem ser construídas com módulos de fibras ocas (hollow fibers), as quais provêm de grandes áreas de membrana por unidade de volume e, dessa forma, resultam em unidade muito compactas.
- Custos de capital moderados

- Custos operacionais moderados

- Fácil operação

- Podem operar com a presença de material particulado na corrente gasosa

- Ocupam área relativamente pequena

- Tecnologia comprovada e estabelecida
- Os poluentes são transferidos para uma nova fase ao invés de serem destruídos

- Somente aplicável para correntes gasosas moderadamente contaminadas

- Não remove a maioria dos compostos orgânicos voláteis
Podem separar seletivamente $\mathrm{CO}_{2}$ e $\mathrm{H}_{2} \mathrm{~S}$ do metano (ex. membranas de acetato e celulose)
Os poluentes são transferidos para uma nova fase ao invés de serem destruídos - Elevadas pressões de trabalho, na faixa de 25 a 40 bar

- Experiência ainda limitada, economicidade e viabilidade técnica ainda não estabelecidas.

Fonte: adaptado de Kennes e Thalasso (1998), Smet e Van Langenhove (1998), Burgess, Parsons e Stuetz (2001), Kennes et al (2001), WEF (2004), Barbosa e Stuetz (2005), Noyola, Morgan-Sagastume e López-Hernández (2006), Bowker (2008). 
Tabela 3 - Principais características e análise comparativa dos principais métodos de tratamento químico de odores: balanço das vantagens e desvantagens

\begin{tabular}{|c|c|c|c|}
\hline Método & Principais características & Vantagens & Desvantagens \\
\hline $\begin{array}{l}\text { Lavador } \\
\text { químico }\end{array}$ & $\begin{array}{l}\text { O princípio básico de um lavador químico } \\
\text { empacotado é a absorção dos compostos } \\
\text { odorantes presentes na corrente gasosa, no } \\
\text { líquido de lavagem. Isso é alcançado pelo in- } \\
\text { tenso contato do gás poluído com a solução } \\
\text { absorvente, no interior de uma coluna empa- } \\
\text { cotada especialmente projetada para propi- } \\
\text { ciar uma grande área interfacial. Produtos } \\
\text { químicos são adicionados à solução lavadora } \\
\text { com o objetivo de incrementar a absorção e } \\
\text { remoção dos compostos odorantes. } \\
\text { - Principais tipos: i) contracorrente, no qual } \\
\text { ambas as correntes (gasosa e líquida) fluem } \\
\text { verticalmente, a gasosa no modo ascendente }\end{array}$ & $\begin{array}{l}\text { - Custos de capital moderados } \\
\text { - Podem operar com a presença de material } \\
\text { particulado na corrente gasosa } \\
\text { - Ocupam pequena área } \\
\text { - Habilidade de suportar cargas variáveis } \\
\text { - Tecnologia comprovada e estabelecida } \\
\text { - Podem remover seletivamente o } \mathrm{H}_{2} \mathrm{~S} \text { pre- } \\
\text { sente nos gases de reatores anaeróbios, } \\
\text { mas podem gerar halometanos }\end{array}$ & $\begin{array}{l}\text { - Custos operacionais elevados } \\
\text { - Desempenho reduzido pela formação de } \\
\text { incrustações } \\
\text { - Necessidade de sistemas complexos de } \\
\text { alimentação de produtos químicos } \\
\text { - Não remove a maioria dos compostos } \\
\text { orgânicos voláteis } \\
\text { - Requer produtos químicos tóxicos e peri- } \\
\text { gosos } \\
\text { - Possibilidade de arraste gasoso dos } \\
\text { produtos químicos não utilizados } \\
\text { - Manutenção elevada } \\
\text { - Geração de halometanos }\end{array}$ \\
\hline
\end{tabular}
e a líquida no modo descendente; ii) horizontal ou fluxo cruzado, no qual a corrente líquida flui verticalmente, enquanto a gasosa atravessa o meio suporte horizontalmente. Trata-se de uma variante dos lavadores químicos, na qual é utilizado um catalisador seletivo para acelerar a reação entre $\mathrm{H}_{2} \mathrm{Se} \mathrm{O}_{2}$ para produzir enxofre. $\mathrm{O}$ catalisador é regenerado e o enxofre é retirado na forma de uma lama, devendo

Oxidação catalítica ser disposto apropriadamente.

- A oxidação térmica, também referenciada como combustão ou incineração, é um processo químico que utiliza $\mathrm{O}_{2}$, ou ar, a elevadas temperaturas para destruir compostos odorantes. A corrente odorante é exposta a elevadas temperaturas, na presença de $\mathrm{O}_{2}$, durante período de tempo suficiente para permitir a oxidação de hidrocarbonetos a

Oxidação $\quad \mathrm{CO}_{2}$ e água.

térmica - Um combustor ou incinerador térmico básico consiste em dois componentes primários: i) queimador, que promove a ignição do combustível na corrente de ar; e ii) câmara que proporciona adequado tempo de residência para o processo de oxidação.

- Tipos principais: câmara de combustão direta, oxidação térmica regenerativa, oxidação térmica recuperativa, oxidação catalítica. - A combustão direta em tochas ("flare") é uma variante da oxidação térmica, a qual usualmente não emprega uma câmara de Combustão combustão. Dessa forma, temperaturas direta suficientemente elevadas não são alcançadas e a combustão dos poluentes pode ser incompleta.

- Refere-se a medidas de controle utilizadas para o tratamento de sulfeto e outros compostos odorantes presentes na fase líquida, antes que estes sejam emitidos para a fase gasosa.

- Produtos químicos são usualmente injetados no interior da corrente líquida ou

Inibição química aplicados às fontes odorantes, visando interromper a produção de sulfeto ou reagir com este no líquido.

- As práticas mais usadas são a adição de agentes oxidantes (ex.: peróxido de hidrogênio, hipoclorito de sódio, permanganato de potássio) ou sais de ferro para propiciar a precipitação do sulfeto.

\section{Custos operacionais baixos}

Pode remover $\mathrm{H}_{2} \mathrm{~S}$ com elevada eficiência (>99,9\%), mas se outros compostos odorantes estiverem presentes, devem ser removidos por outro tipo de lavador.

Pode remover seletivamente $\circ \mathrm{H}_{2} \mathrm{~S}$ presente nos gases de reatores anaeróbios.

Pode ser mais barato do que a adsorção com carvão ativado granulado na faixa de concentração de 20 a 60 ppmv.

- Consome menos combustível e utiliza materiais construtivos mais baratos do que a oxidação térmica.

- Ocupa pequena área

- Efetivo para todos os tipos e concentrações de compostos odorantes

- Apropriado para cargas muito elevadas

Desempenho uniforme e confiável

Eficiências na faixa de 90 a 99\%

- Potencial de geração de energia útil (calor, eletricidade)

Custos de capital baixos

Custos operacionais baixos

Ocupa pequena área

Boa alternativa para a queima de biogás em pequenas estações de tratamento

Custos de capital baixos

Agentes oxidantes: efetivos para o controle de sulfetos em tubulações por gravidade e por pressão (ex.: peróxido de hidrogênio, hipoclorito de sódio); efetivos para uma ampla faixa de odorantes (ex.: hipoclorito de sódio); instalação simples.

Sais de ferro: econômico para o controle de sulfeto em tubulações por gravidade e por pressão; instalação simples
Custos de capital elevados

A combustão incompleta pode gerar compostos sulfurados
- Custos de capital elevados

- Custos operacionais elevados (demanda de energia)

- Economicamente viáveis apenas para o tratamento de correntes com concentrações elevadas de compostos orgânicos voláteis.

- Usualmente requer combustível adicional

- Efetividade e custo altamente dependentes de três fatores: temperatura, tempo de residência e turbulência

- A combustão incompleta pode resultar na geração de compostos sulfurados

- Gera uma corrente secundária de resíduos
A combustão incompleta pode resultar na geração de compostos sulfurados

Perda de potencial de energia quando o calor não é recuperado

Aplicável principalmente para pequenas estações de tratamento

\section{- Custos operacionais elevados}

- Agentes oxidantes: preocupação quanto à segurança e elevados custos dos produtos químicos (ex.: peróxido de hidrogênio, hipoclorito de sódio); dificuldade de manuseio (ex.: permanganato de potássio).

- Sais de ferro: não efetivo para compostos que não $\circ \mathrm{H}_{2} \mathrm{~S}$; controle de sulfeto em baixos níveis pode ser difícil; aumenta a produção de lodo.

- A injeção química é a técnica de controle menos efetiva, usualmente apresentando efetividade marginal (redução da detecção de odor inferior a 50\%) 
Tabela 4 - Principais características e análise comparativa dos principais métodos de tratamento bioquímico de odores: balanço das vantagens e desvantagens

\begin{tabular}{|c|c|}
\hline Método & Principais características \\
\hline $\begin{array}{l}\text { Biofiltro pré- } \\
\text { fabricado }\end{array}$ & $\begin{array}{l}\text { - Constituído de um único reator (ab- } \\
\text { sorção e biodegradação ocorrem no } \\
\text { mesmo reator) com biomassa e fase } \\
\text { aquosa imobilizados } \\
\text { - O gás a ser tratado é forçado através } \\
\text { de um meio suporte constituído de ma- } \\
\text { terial natural (carvão, turfa, solo, cavaco } \\
\text { de madeira, composto etc.) ou sinté- } \\
\text { tico, no qual micro-organismos ficam } \\
\text { aderidos na forma de um biofilme. Os } \\
\text { compostos voláteis biodegradáveis são } \\
\text { absorvidos pelo meio suporte e pelo } \\
\text { biofilme, sendo biologicamente oxida- } \\
\text { dos a substâncias menos prejudiciais }\end{array}$ \\
\hline
\end{tabular}

\begin{tabular}{|c|c|}
\hline $\begin{array}{l}\text { Biofiltros } \\
\text { estruturados } \\
\text { e não- } \\
\text { estruturados }\end{array}$ & $\begin{array}{l}\text { - Constituído de um único reator (ab- } \\
\text { sorção e biodegradação ocorrem no } \\
\text { mesmo reator) com biomassa e fase } \\
\text { aquosa imobilizados } \\
\text { - O gás a ser tratado é forçado através } \\
\text { de um meio suporte constituído de } \\
\text { material natural (carvão, turfa, solo, } \\
\text { cavaco de madeira, composto etc.) ou } \\
\text { sintético, no qual microrganismos ficam } \\
\text { aderidos na forma de um biofilme. Os } \\
\text { compostos voláteis biodegradáveis são } \\
\text { absorvidos pelo meio suporte e pelo } \\
\text { biofilme, sendo biologicamente oxida- } \\
\text { dos a substâncias menos prejudiciais }\end{array}$ \\
\hline
\end{tabular}

Constituído de um único reator (absorção e biodegradação ocorrem no mesmo reator) com biomassa imobilizada e fase aquosa móvel.

Biofiltro

percolador

O gás a ser tratado é forçado através de uma coluna não submergida,

preenchida com material de enchimento coberto por um biofilme ativo. No topo do material de enchimento, é feita a aspersão de uma fase líquida que é continuamente recirculada.

Constituído de um lavador e de um biorreator (a absorção ocorre predominantemente no lavador enquanto a biodegradação ocorre no biorreator) com uma fase aquosa móvel. No biorreator há

Biolavador a predominância de biomassa suspensa.

O gás a ser tratado é forçado no sentido ascendente através do lavador, enquanto a fase líquida, retirada do biorreator, é distribuída sobre o topo do meio suporte contido na torre lavadora.

Constituído de um reator único (a difusão e a biodegradação ocorrem no mesmo reator) com biomassa imobilizada ou em suspensão e uma fase aquosa móvel.

Biorreator de - Os poluentes presentes na fase membrana gasosa são transferidos através de uma membrana até uma fase líquida biologicamente ativa presente no outro lado da membrana onde podem ser degradados.

Consiste na utilização de uma unidade existente de tratamento de esgoto para o tratamento dos compostos odorantes. Os gases a serem tratados são trans-

Sistemas aeróbios de
fase líquida feridos, via sopradores, para difusores submersos no tanque de aeração, onde os contaminantes são absorvidos na fase líquida e posteriormente biodegradados.

\section{Vantagens}

Custos de capital moderados

Custos operacionais baixos

Partida e operação simples

Vida útil do meio suporte mais elevada que a dos biofiltros não pré-fabricados

Aplicável para a redução dos compostos odorantes encontrados em ETE

Aplicável para o tratamento de grandes vazões e baixas concentrações de odorantes sulfurados

Área superficial específica mais elevada que a dos biofiltros percoladores (300 a 1.000 $\mathrm{m}^{2} / \mathrm{m}^{3}$ )

Proporcionam a degradação de compostos menos solúveis em água

Custos de capital baixos

Custos operacionais baixos

Fácil e simples de construir

Partida e operação simples

Aplicável para a redução dos compostos odorantes encontrados em ETE

Aplicável para grandes vazões e baixas concentrações de odorantes sulfurados Área superficial específica mais elevada que a dos biofiltros percoladores (300 a 1.000 $\mathrm{m}^{2} / \mathrm{m}^{3}$ )

Proporcionam a degradação de compostos menos solúveis em água

Custos de capital baixos a moderados

Custos operacionais baixos

Projeto simples e flexível

Partida e operação simples

Apropriado para correntes gasosas moderadamente contaminadas

Possibilidade de adição de nutrientes e de controle de $\mathrm{pH}$

Bom controle das condições das reações ( $\mathrm{pH}$, nutrientes etc.)

Elevada estabilidade operacional

Possibilidade de evitar acumulação de produtos

Ocupam menor área que os biofiltros

Baixa perda de pressão

Elevada transferência de massa

Apropriado para correntes gasosas alta-

mente contaminadas

Bom controle das condições das reações $(\mathrm{pH}$, nutrientes etc.)

As vazões de gás e de líquido podem ser variadas independentemente

A escolha cuidadosa do material da membrana pode possibilitar a extração seletiva ou a retenção seletiva de compostos na fase gasosa.

A presença da membrana previne a contaminação da fase gasosa por micro-organismos (apropriado para o tratamento de ar interior)

Não contém partes móveis

Fácil ampliação de escala

Uso de unidades existentes (não há demanda de área nem de investimentos de capital) Custos operacionais baixos

Projeto simples e flexível

Operação simples

Não há necessidade de produtos químicos

Apropriado para correntes gasosas moderadamente contaminadas

Aplicável para grandes vazões de correntes gasosas contaminadas

\section{Desvantagens}

Critérios de projeto ainda em desenvolvimento

Apropriados somente para o tratamento de baixas concentrações de odorantes

Elevado tempo de residência requerido.

Ocupam elevada área e requerem grande volume de meio suporte

Controle limitado das condições das reações (devido à inexistência de uma fase líquida)

Caminhos preferenciais da corrente gasosa são usualmente um problema

Adaptação lenta a flutuações na concentração dos gases odorantes

Meio suporte sintético não contém os nutrientes requeridos pelos microrganismos. Necessidade de adição de nutrientes na água de irrigação.

Critérios de projeto ainda em desenvolvimento

Apropriados somente para o tratamento de baixas concentrações de odorantes

Elevado tempo de residência requerido.

Ocupam elevada área e requerem grande volume de meio suporte

Controle limitado das condições das reações (devido à inexistência de uma fase líquida)

Caminhos preferenciais da corrente gasosa são usualmente um problema

- Vida útil limitada do meio suporte orgânico (substituição necessária com poucos anos)

Meio suporte inorgânico usualmente não contém os nutrientes requeridos pelos micro-organismos. Necessidade de adição de nutrientes na água de irrigação.

Chuvas intensas podem causar problemas operacionais. Necessidade de cobertura.

- Critérios de projeto ainda em desenvolvimento.

Área superficial específica inferior à dos biofiltros (100 a $300 \mathrm{~m}^{2} / \mathrm{m}^{3}$ ).

Elevado tempo de residência requerido (porque a dissolução na fase líquida é a etapa limitante). Necessidade de recirculação da corrente gasosa.

Ocupam elevada área e requerem grande volume de meio suporte

Controle operacional limitado

Caminhos preferenciais podem ser problema

Custos de capital elevados

Custos operacionais elevados

Perda de micro-organismos de crescimento lento

Períodos de paralisação de poucos dias são prejudiciais.

Produção de biomassa excedente.

Disposição final do lodo excedente.

Procedimento de partida complexo.

Custos de capital elevados

Custos operacionais moderados a elevados

Estabilidade operacional de longo termo não comprovada

Experiência limitada a testes de laboratório e instalações piloto (ainda a ser confirmado em escala plena).

- Utilização pode se limitar a poluentes altamente solúveis.

Possibilidade de retenção de sólidos excedentes no interior do reator.

Dissolução da corrente gasosa é a etapa limitante Controle do processo pode ser difícil Consistência de desempenho questionável Apropriado somente para o tratamento de $\mathrm{H}_{2} \mathrm{~S}$ Requer pré-existência de sistemas aeróbios na ETE

Fonte: adaptado de Kennes e Thalasso (1998), Burgess, Parsons e Stuetz (2001), WEF (2004), Barbosa e Stuetz (2005), Noyola, Morgan-Sagastume e López-Hernández (2006). 


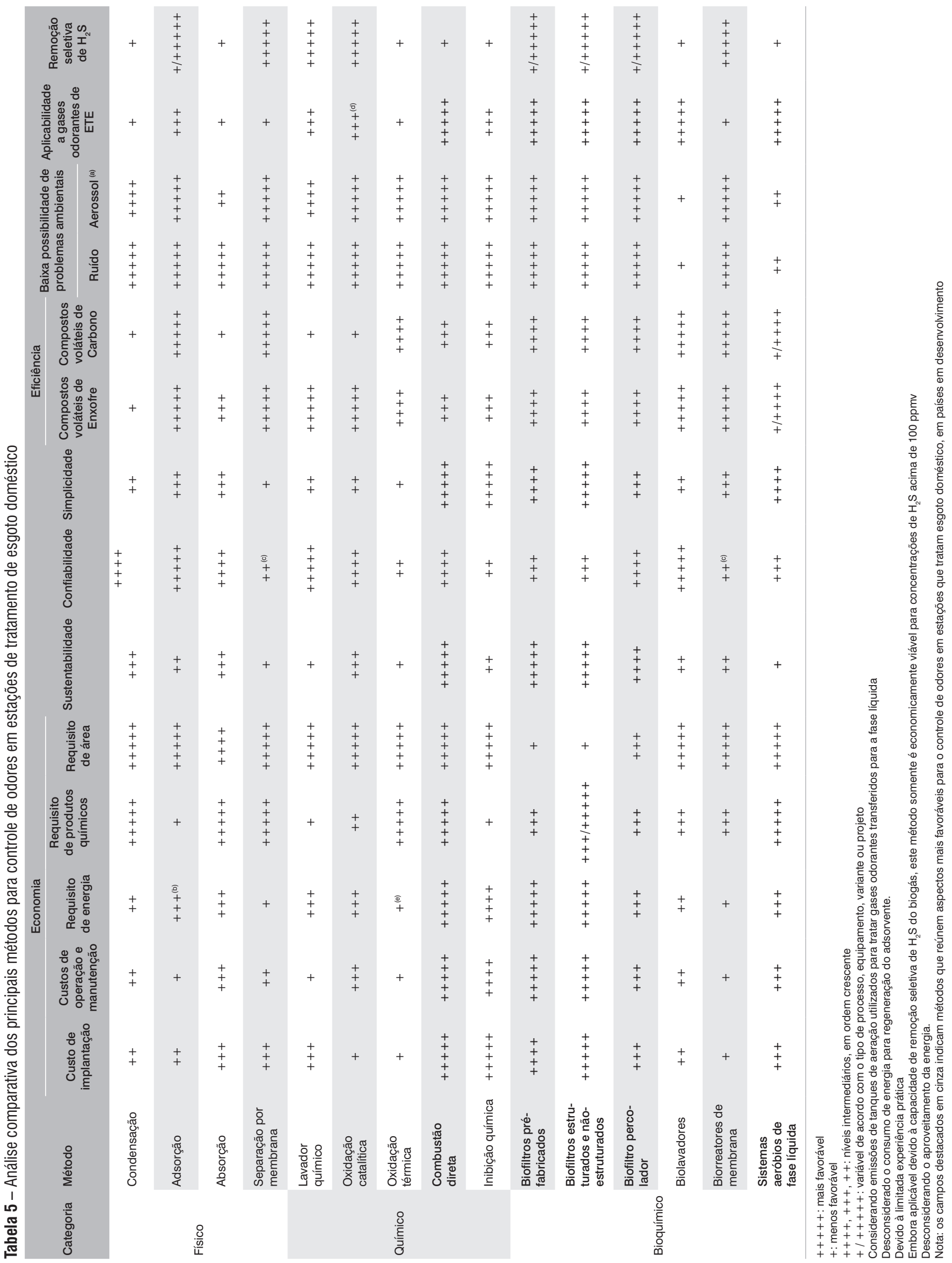


entre diferentes aspectos considerados na seleção de alternativas de gerenciamento de emissões odorantes em países desenvolvidos e em países em desenvolvimento. Países emergentes, como o Brasil, estariam em uma situação intermediária ou de transição, e a situação deve ser verificada caso a caso, podendo apresentar aspectos mais próximos aos dos países desenvolvidos ou em desenvolvimento.

A Tabela 5 apresenta uma análise comparativa dos principais métodos físicos, químicos e bioquímicos relativa ao controle de odores produzidos em estações de tratamento de esgoto doméstico. As principais características, vantagens e desvantagens de cada método de abatimento de odores (Tabelas 2, 3 e 4) foram ranqueadas de acordo com as faixas usuais de aplicação (Figura 1) e aspectos considerados importantes e críticos no Brasil, conforme mostrado na Figura 2.

\section{Considerações finais}

Embora existam diversos métodos para o tratamento de emissões odorantes em estações de tratamento de esgoto, infere-se que muitos são sofisticados, de elevado custo de implantação e operação e, muitas vezes, não apropriados para o tratamento de odores emitidos em reatores anaeróbios tratando esgoto doméstico. À exceção da adsorção, os demais métodos físicos e químicos são aplicáveis principalmente para o tratamento de poluentes em elevadas concentrações, todavia, nos reatores anaeróbios tratando esgoto doméstico, os gases odorantes encontram-se usualmente presentes em baixas concentrações. Ademais, a análise qualitativa das principais características de cada método indica que a combustão direta e os métodos bioquímicos, e particularmente os biofiltros, são os que reúnem o maior conjunto de vantagens para o tratamento de gases residuais emitidos em reatores anaeróbios para tratamento de esgoto doméstico, notadamente se considerados os fatores críticos e prioritários em países em desenvolvimento, como sustentabilidade, simplicidade e baixos custos de implantação e operação.

A remoção do $\mathrm{H}_{2} \mathrm{~S}$ presente no biogás pode ser alcançada por meio da oxidação térmica, utilizando-se o metano como combustível. No entanto, pode ocorrer a combustão incompleta do $\mathrm{H}_{2} \mathrm{~S}$ no caso de queimadores convencionais (abertos). Para se garantir a combustão completa do sulfeto, devem ser utilizados queimadores fechados, com câmara de combustão. A recuperação de energia do biogás para fins mais nobres (ex.: combustível veicular, injeção na linha de gás natural) pode exigir a utilização de algum método que possibilite a remoção seletiva do $\mathrm{H}_{2} \mathrm{~S}$ e a manutenção do metano no biogás.

Diferentes alternativas podem ser consideradas para a remoção do sulfeto dissolvido no efluente do reator, a exemplo do stripping em câmara de dissipação, seguido de tratamento em biofiltro. No entanto, se a estação de tratament de esgoto (ETE) dispuser de alguma sistema aeróbio de fase líquida para o pós-tratamento do efluente anaeróbio, esta será a forma mais simples e de melhor custo-benefício para o tratamento de odores, uma vez que a oxidação bioquímica do $\mathrm{H}_{2} \mathrm{~S}$ pode ser facilmente alcançada nesses sistemas.

\section{Referências}

SILVA, M.B. et al. Comparação do desempenho de diferentes filtros biológicos na remoção de H2S do ar em estações de tratamento de esgoto sanitário. In: $24^{\circ}$ CONGRESSO BRASILEIRO DE ENGENHARIA SANITÁRIA E AMBIENTAL, Belo Horizonte, ABES, 2007.

AL-SHAMMIRI, M. Hydrogen sulfide emission from the Ardiyah sewage treatment plant in Kuwait, Desalination, v. 170, p. 1-13, 2004.

Barbosa, V.L.; Stuetz, R.M. Treatment of hydrogen sulfide in biofuels. In: Lens, P. et al. (Ed.). Biofuels for fuel cells: renewable energy from biomass fermentation. London: IWA Publishing, 2005.

BOHN H.L. Bioprocessing of organic gases in waste air. Symposium on Bioremediation and Bioprocessing. In: 205 AMERICAN CHEMICAL SOCIETY, Denver, p. 287-289, 1993.

Bowker, R.P.G. Treating odors. 2008. Bowker and Associates Inc. http:// www.bowkerandassoc.com/index.html.

Burgess, J.E.; Parsons, S.A.; Stuetz, R.M. Developments in odour control and waste gas treatment biotechnology: a review. Biotechnology Advances, v. 19, n. 1, p. 35-63, 2001.
JOBBÁGY, A.l. et al. Sewer system odour control in the Lake Balaton area, Water Science and Technology, v. 30, n. 1, p. 195-204, 1994.

Kennes, C.; Thalasso, F. Waste gas biotreatment technology. Journal of Chemical. Technology and Biotechnology, v. 72, p. 303-319, 1998.

Kennes, C., Veiga, M.C.; Prado, O. Non biological treatment technologies. In: KENNES, C.; VEIGA, M.C. (Ed.). Bioreactors for waste gas treatment. Dordrecht: Kluwer Academic Publishers, 2001.

MATOS, J.S.; AIRES, C.M. Mathematical modelling of sulphides and hydrogen sulphide gas build-up in the cosas do estoril sewerage system. Water Science and Technology. v. 31, n. 7, p. 255-261, 1995.

Noyola, A., Morgan-Sagastume, J.M.; López-Hernández, J.E. Treatment of biogas produced in anaerobic reactors for domestic wastewater: odour control and energy/resource recovery. Reviews in Environmental Sciences and Bio/Technology, v. 5, p. 93-114, 2006.

PAGLIUSO, J.D.; PASSIG, F.H.; Villela, L.C.H. Odour treatment and energy recovery in anaerobic sewage treatment plants. In: VII OFICINA E SIMPOSIO LATINO-AMERICANO DE DIGESTÃO ANAERÓBIA, México, IWA/FEMISCA, 2002. 
SILVA, M.B., et al. Comparação do desempenho de diferentes filtros biológicos na remoção de $\mathrm{H}_{2} \mathrm{~S}$ do ar em estações de tratamento de esgoto sanitário. In: 24 CONGRESSO BRASILEIRO DE ENGENHARIA SANITÁRIA E AMBIENTAL, Belo Horizonte, ABES, 2007.

Smet, E.; van Langenhove, $\mathrm{H}$. Abatement of volatile organic sulfur compounds and odorous emissions from the bioindustry. Biodegradation, v. 9, p. $273-284,1998$.

SOUZA, C.L.; CHERNICHARO, C.A.L.; MELO, G.C.B. Methane and hydrogen sulfide emissions in UASB reactors treating domestic wastewater. In: 12th CONGRESS ON ANAEROBIC DIGESTION, México, IWA, 2010.

SOUZA, C.L. Estudo das rotas de formação, transporte e consumo dos gases metano e sulfeto de hidrogênio resultantes do tratamento de esgoto doméstico em reatores UASB. Tese (Doutorado em Saneamento, Meio Ambiente e Recursos Hídricos) - Escola de Engenharia da UFMG, 2010.

van Langenhove, $\mathrm{H}_{\text {.; }}$ de Heyder, B. Biotechnological treatment of sewage odours'. In: STUETZ, R.M.; FRECHEN, F.-B. (Ed.). Odours in Wastewater Treatment: measurement, modelling and control. London: IWA Publishing,, 2001. p. 396-414.

von Sperling, M. Comparison among the most frequently used systems for wastewater treatment in developing countries. Water Science and Technology, v. 33, n. 3, p. 59-72, 1996.

WEF. Control of odors and emissions from wastewater treatment plants. Alexandria: Water Environment Federation, 2004. 